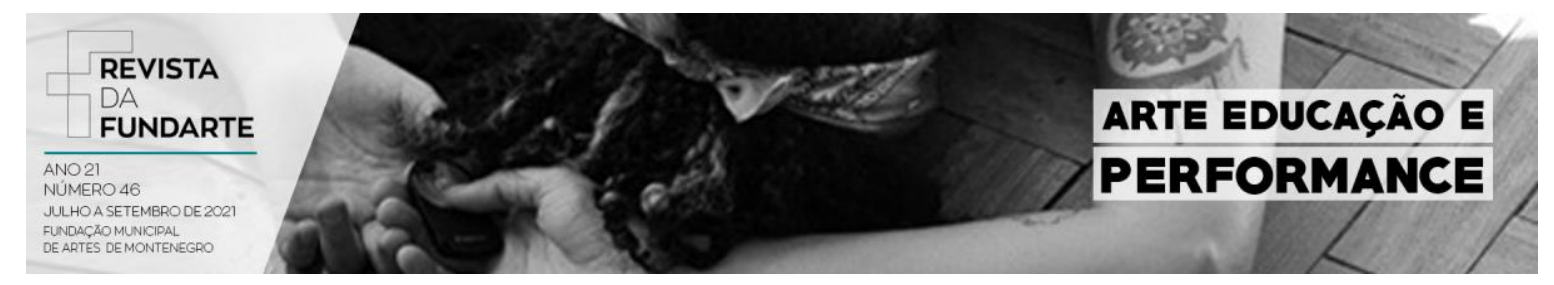

\title{
EM ESTADO-POÉTICO: INSURGÊNCIAS REFLEXIVAS SOBRE O PESQUISAR EM EDUCAÇÃO
}

\author{
Bruno Felix da Costa Almeida
}

DOI: http://dx.doi.org/10.19179\%2F2319-0868.854

ALMEIDA, Bruno Felix da Costa. Em estado-poético: insurgências reflexivas sobre o pesquisar em educação. Revista da FUNDARTE. Montenegro, p.01-16, ano 21, no 46, setembro de 2021.

Disponível em: http://seer.fundarte.rs.gov.br/index.php/RevistadaFundarte/issue/archive $>30$ de setembro de 2021. 


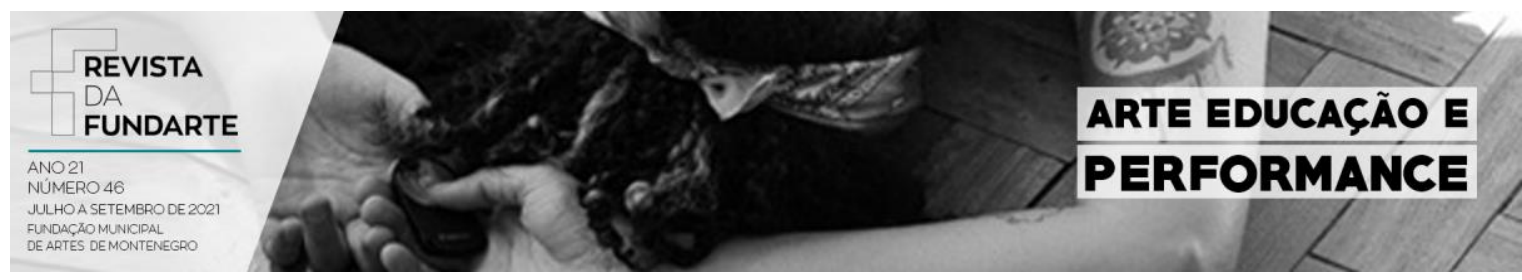

\title{
EM ESTADO-POÉTICO: INSURGÊNCIAS REFLEXIVAS SOBRE O PESQUISAR EM EDUCAÇÃO
}

Bruno Felix da Costa Almeida ${ }^{1}$

\begin{abstract}
Resumo: O Ensaio apresenta algumas reflexões emergidas junto a Arte de Ser e de Estar músicodocente-pesquisador em estrita correlação às ações de pesquisar e refletir em um processo de doutoramento em educação. Tal insurgência foi provocada a partir do estudo dos textos "Carta a um jovem investigador em educação" (NÓVOA, 2015) e "A desmonumentalização do conhecimento escrito e arquivístico" (SANTOS, 2019), os quais constituem a trama-problematizadora, a fim expor o que se pensa sobre a ação de pesquisar, bem como os modos de apresentação dos fatos históricos, considerando versões da história. Contudo, discute-se às inquietudes de quem o escreve diante da ação de pesquisar em educação.
\end{abstract}

Palavras-chave: Pesquisa em Educação; Conhecimento Histórico; Estado-poético.

\section{IN POETIC STATE: REFLEXIVE INSURGENCIES ON RESEARCH IN EDUCATION}

Abstract: The Essay presents some reflections emerged with the Art of Being and Being musicianteacher-researcher in strict correlation to the actions of researching and reflecting in a doctoral process in education. This insurgency was provoked from the study of the texts "Letter to a young researcher in education" (NÓVOA, 2015) and "The desmonumentalization of written and archival knowledge" (SANTOS, 2019), which constitute the problematizing plot, in order to expose what one thinks about the action of research, as well as the ways of presenting historical facts, considering versions of history. However, it discusses the concerns of those who write it in the face of the action of researching in education.

Keywords: Research in Education; Historical Knowledge; Poetic State.

\section{Introdução à Proposta de Pensamento}

A Arte de Ser e de Estar pode emergir de diferentes formas, sentimentos, lugares, encontros e desencontros. Por sua vez, em colocando-a em estrita correlação à Educação, ambas se unem diante de um processo de transfiguração

\footnotetext{
${ }^{1}$ Doutorando do Programa de Pós-Graduação em Educação, da Universidade Federal de Santa Maria (UFSM), e do Programa de Pós-Graduação em Educação, da Universidade de Santa Cruz do Sul (UNISC) - Bolsista PROSUC/CAPES - Modalidade II. Mestre em Educação, Especialista em Educação Musical e Licenciado em Música, pela Universidade Estadual do Rio Grande do Sul (UERGS). Especialista Ensino de Arte, pela Universidade Cidade de São Paulo (UNICID). Bacharel em Música - Habilitação em Piano, pela Universidade Cruzeiro do Sul (UNICSUL).
}

ALMEIDA, Bruno Felix da Costa. Em estado-poético: insurgências reflexivas sobre o pesquisar em educação. Revista da FUNDARTE. Montenegro, p.01-16, ano 21, no 46, setembro de 2021.

Disponível em: http://seer.fundarte.rs.gov.br/index.php/RevistadaFundarte/issue/archive $>30$ de setembro de 2021 . 


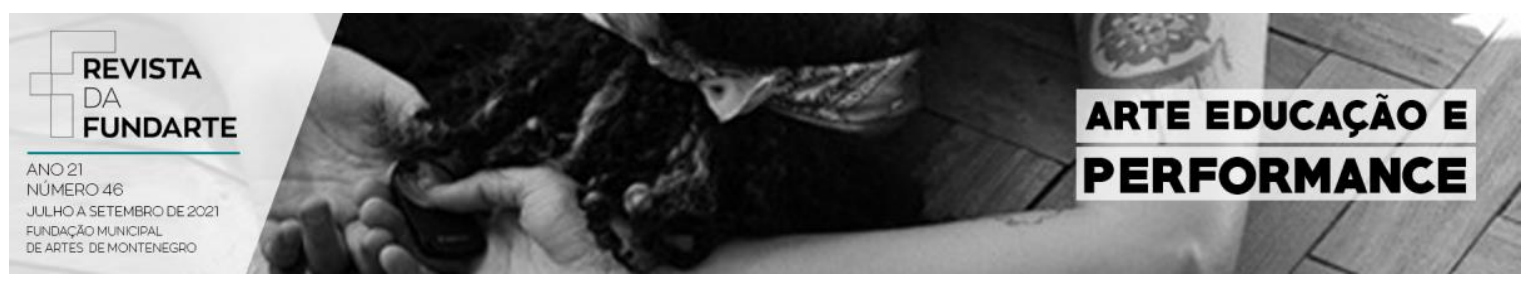

deste Eu (músico-docente-pesquisador), que se forma e, principalmente, se transforma nas relações estabelecidas entre os Espaços e os Tempos de Viver com àqueles que propiciam que a Arte Seja, através da Educação, singular diante do coletivo nesse momento que se (trans)figura o cenário planetário dessa década de vinte do segundo milênio.

Como nos lembra Herrigel (1995, p. 87), entre o momento em que somos iniciados à Arte e os que se seguem através do(s) caminho(s) que buscamos percorrer, "vencendo-se de si mesmo e de si mesmo se libertando por etapas", é possível espiritualizar a habilidade que nos perpassa e que nos provoca a Ser o que somos.

Nesse sentido, percebo que este Eu só pode Ser em conjunto com outras singularidades, com outras pluralidades. E é, em sabendo disso, que a escrita desse Ensaio - sobre os desafios de ser músico-docente-pesquisador em TempoPlanetário-2020 - se coloca em caminhos que transitam entre o Singular e o Plural.

Esclarece-se que os caminhos a serem percorridos São (no presente, pois estão em acontecimento) e Serão (no futuro, à serem trilhados) circunscritos, considerando a escrita na Primeira Pessoa, ou seja, que descreve a partir do Eu (este que vos escreve) e do Nós (este Eu inserido em seu coletivo de Ser com os outros Eu(s) que o cerca); na Segunda Pessoa, em busca de contextualizar com quem se fala: Contigo (Tu) e, também, Convosco (Vós), a fim de propiciar outras reflexões a partir do que aqui se apresenta enquanto pensamento-reflexivo; culminando na Terceira Pessoa, em se tratando de quem este Eu está a falar: Dele (Ele) e Deles (Eles), que juntos fazem emergir, através dessa textualização, possibilidades de Ser, Sendo.

Em outras palavras, a textualização desse excerto se configura, em/na transição com as Pessoas - nos sentidos gramatical e inter-relacional -; a partir das inquietações acadêmicas de um Eu (músico-docente-pesquisador) que Vive entre as possibilidades de Ser músico-docente - em se tratando de suas relações profissionais - e Ser, também, professor-pesquisador - em se tratando de sua

ALMEIDA, Bruno Felix da Costa. Em estado-poético: insurgências reflexivas sobre o pesquisar em educação. Revista da FUNDARTE. Montenegro, p.01-16, ano 21, № 46, setembro de 2021.

Disponível em: http://seer.fundarte.rs.gov.br/index.php/RevistadaFundarte/issue/archive $>30$ de setembro de 2021. 


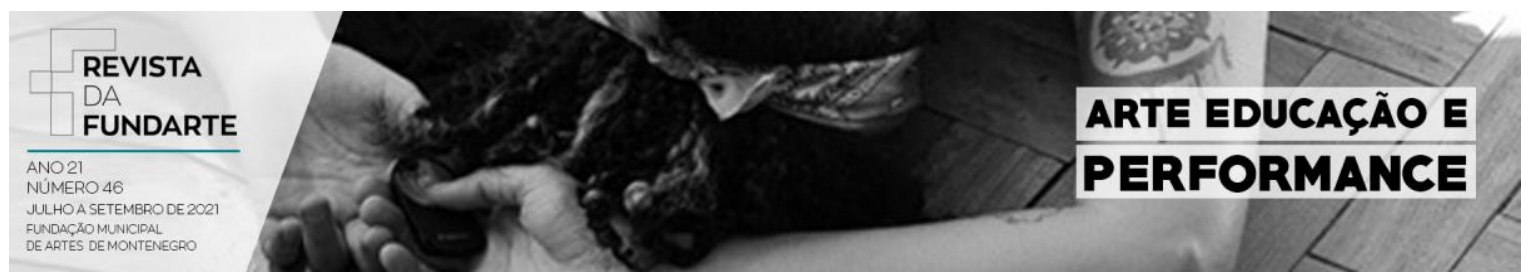

constante (trans)formação através do Educar e do se Educar durante seu processo de Doutoramento em Educação.

\section{Pensando à Pesquisa}

Os desafios de um Eu (músico-docente) passa a Ser transformado ao passo que, em suas inquietudes, compreende a incessante necessidade da busca de Ser, também, o Eu (professor-pesquisador), a fim de refletir sobre as possibilidades de Ser através e junto de uma pesquisa de Doutorado em Educação. E é sobre esse aspecto que a História atravessa à Pesquisa.

Elaborar uma proposta de Tese de Doutorado é um desafio para mim: um sujeito que, através desse discurso, busca evidenciar o Eu pesquisador que interroga e Se interroga na complexidade de Ser e Estar sempre em transformação, diante do desafio de Ser músico-docente-pesquisador, que caminha entre o limiar prático-experiencial (as vivências na escola) e o limiar acadêmico-científico (a universidade).

As marcas de um caminho vivenciado, experienciado, compartilhado e, principalmente, construído na interlocução emergente entre as músicas e as pessoas, como nos remete Kraemer (2000), emergem nas perspectivas de se aventurar no desafio da transformação a partir do que já existe, de desconectar o conectado e reconectar os caminhos, na busca de tecer a trama complexa que é viver vivendo na/e através da Educação, à qual nos provoca Morin (2015).

Compreendo que a Educação é plural, porque existem singularidades em cada um de nós. Singularidades que nos permitem (re)conectarmos com o(s) meio(s) e com o(s) outro(s), para sermos o que somos culturalmente. Heidegger (2015, p. 85), contribui à esta reflexão quando ao tratar sobre "ser e tempo", corrobora que "a 'essência' da presença está em sua existência". Em outras palavras, existir nos torna presente ao universo que nos proporciona Ser no Tempo e Ser através do Espaço-Tempo.

ALMEIDA, Bruno Felix da Costa. Em estado-poético: insurgências reflexivas sobre o pesquisar em educação. Revista da FUNDARTE. Montenegro, p.01-16, ano 21, no 46, setembro de 2021.

Disponível em: http://seer.fundarte.rs.gov.br/index.php/RevistadaFundarte/issue/archive $>30$ de setembro de 2021. 


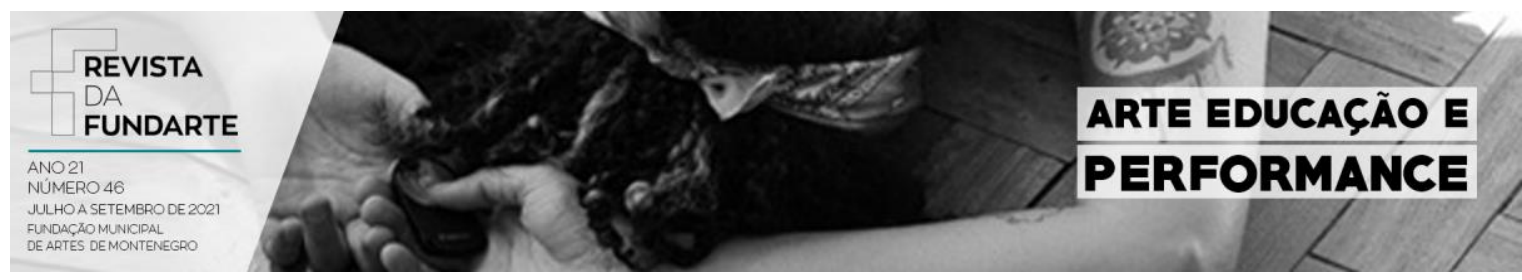

E é deste Tempo que nos permite Ser, que o Viver e o Educar surgem, para juntos, entrelaçar os saberes em Educação e Música, eixos que me movem na complexidade temporal em que vivo.

Acredito, assim como Delors e colaboradores (1996) propõem enquanto desafio à Educação de nosso século, na eminente importância dos "Quatro Pilares para a Educação", quais sejam: "Aprender a conhecer", que nos proporciona saberes e conhecimentos à vida a partir do mundo em que vivemos (p. 91); "Aprender a fazer", que, por sua vez, é entendido como indissociável do Aprender a conhecer, no entanto, trata-se das aproximações relacionadas à formação diante de uma profissão - da articulação de práticas de conhecimentos através da educação (p. 93); "Aprender a viver juntos, aprender a viver com os outros", que relaciona-se ao que efetivamente a aprendizagem representa, ou seja, do compartilhar, do reconhecer e se reconhecer na singularidade e na diferença existente nos modos de ser e de existir (p. 96); e "Aprender a ser", o que corrobora a importância de se constituir com os outros, através das interlocuções culturais, da diversidade - o que proporciona à educação "conferir a todos os seres humanos a liberdade de pensamento, discernimento, sentimentos e imaginação de que necessitam para desenvolver os seus talentos e permanecerem, tanto quanto possível, donos de seu próprio destino" (p. 100).

Diante dessa relação, estabelecida entre o Ser, o Tempo e a Educação, me coloco a refletir sobre o constituir-se Pesquisador em correlação com as percepções sobre o (re)conhecimento dos fatos através da História. Tal insurgência foi provocada em mim após o estudo de dois textos.

O primeiro: "Carta a um jovem investigador em educação", de António Nóvoa, publicado no ano de 2015, provocou-me inquietações acerca da condução eficiente de pesquisa em educação. Na relação entre as ações pesquisar e questionar, pesquisar e problematizar, pesquisar e refletir, pesquisar para Ser pesquisador, além de outras formas de interlocução com o termo pesquisar, coloco-me a problematizar

ALMEIDA, Bruno Felix da Costa. Em estado-poético: insurgências reflexivas sobre o pesquisar em educação. Revista da FUNDARTE. Montenegro, p.01-16, ano 21, № 46, setembro de 2021.

Disponível em: http://seer.fundarte.rs.gov.br/index.php/RevistadaFundarte/issue/archive $>30$ de setembro de 2021. 


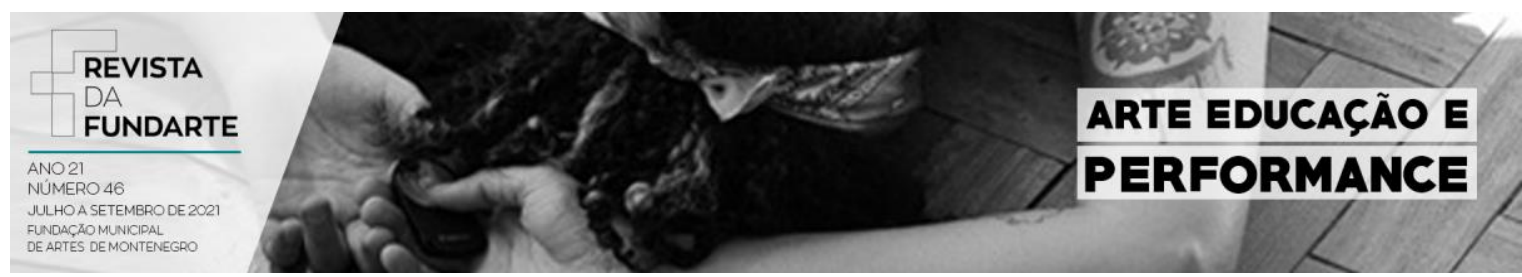

o aprimoramento científico em e através da pesquisa com ênfase nos conselhos relacionados por Nóvoa (2015), destinados ao jovem pesquisador em educação.

E o segundo: "A desmonumentalização do conhecimento escrito $e$ arquivístico", que configura um dos capítulos da obra "O fim do império cognitivo: a afirmação das epistemologias do sul', de Boaventura de Sousa Santos, publicada no ano de 2019 - o qual se trata de afirmações que corroboram a importância de se propor uma perspectiva de entendimento histórico diferenciado, com vistas a evidenciar informações possivelmente negligenciadas. E é, portanto, diante desse contexto que faço algumas problematizações acerca das considerações relacionadas pelo autor.

Em considerando os textos como eixos de reflexão, proponho-me, a partir das palavras de Nóvoa (2015), a iniciar a exposição de minhas insurgências em estadopoético - através da escrita - "uma carta permite maiores liberdades do que outros estilos e, por isso, me atrevo a dar-vos oito conselhos, e ainda, um nono, porque nele vai tudo o que me inquieta, tudo o que procuro na vida" (NÓVOA, 2015, p. 13). Logo é sobre esta carta, que também me inquieta e me atravessa com provocações, que se trata a seção a seguir.

\section{Carta à um Jovem Pesquisador: Para quê? Por quê?}

Considera-se - em um âmbito do senso popular, diga-se de passagem - que as pessoas com mais experiências, aquelas que já passaram por diversos momentos de vivências distintas, quer sejam através de momentos pessoais relacionados às suas ações de convivência consigo e com o outro, com as relações com seus sentimentos e suas intuições, com as suas interações psicológicas com o singular e o coletivo, e através das mais diferentes formas de conhecimento de mundo, ou seja, conhecimentos que puderam emergir sobre o mundo estando nele e com ele, são essas as pessoas que, de alguma maneira, podem dizer mais sobre a vida, sobre as coisas. Por quê?

ALMEIDA, Bruno Felix da Costa. Em estado-poético: insurgências reflexivas sobre o pesquisar em educação. Revista da FUNDARTE. Montenegro, p.01-16, ano 21, no 46, setembro de 2021.

Disponível em: http://seer.fundarte.rs.gov.br/index.php/RevistadaFundarte/issue/archive > 30 de setembro de 2021. 


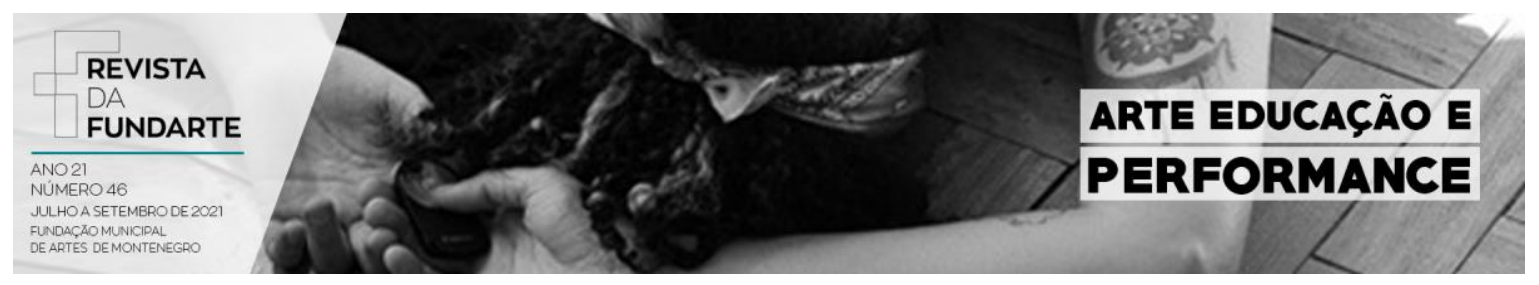

Porque pela vida já passara, na diversidade dos acontecimentos, por diversas situações e por estarem exposta ao exposto que o mundo oferece na emergência de sua existência com todos os seres naturais advindo dele por mais tempo.

E mais tempo é sinal de mais conhecimento?

No entanto, o conhecimento dessas pessoas, fruto de suas relações humanas, sociais, culturais, psicológicas, perceptivas e de todas as outras imagináveis, é intransferível, limita-se à possibilidade do compartilhado. Compartilha-se o que se viveu, o que se vive junto, e propõe-se a compartilhar o que virá a viver diante de uma proposta para o estar junto, ao estar com, ao estar entre, ao estar difundido ou repelido no ato (na ação) de viver a experiência no mundo, podendo se considerar parte dele ou não (tudo depende de como tu interpretas a sua presença nele).

Em sabendo disso, escrever uma carta à um jovem pesquisador, e ainda, sendo mais politicamente correto, à uma jovem pesquisadora e à umx jovem pesquisadxr, para quê? Para aconselhar? Para compartilhar a minha experiência? Para dizer qual o melhor caminho a ser seguido? Para dar conselhos? Para me fazer útil? Para validar o que aprendi nessa incessante caminha de existir? Para me fazer presente? Ora, quanta ironia!

Escrever uma carta, hesitando ou não hesitando em fazê-la, soa-me mais como um desabafo para dizer para Mim sobre Mim. Dizer ao outro o que vivi através da carta, contando-lhes o que para mim foi bom e o que poderia ser evitável. Não posso dizer à qual escolha alguém pode fazer diante do seu próprio ato - ação de estar no mundo, com o mundo e para o mundo - de pesquisar. Posso falar, posso escrever, posso (com)dizer na minha singularidade, na minha forma de me fazer presente no coletivo, o que fiz e o que, talvez, não faria de novo.

Posso dizer o que acolho como uma profundeza diante de minha ação de buscar o que quero saber, mas o como fazer isso, cabe a mim descobrir, assim como cabe a ti descobrir o como fará para descobrir o que se descobre na experiência. Por quê? Porque a experiência é sua. Porque a "regra" (e a escrevo

ALMEIDA, Bruno Felix da Costa. Em estado-poético: insurgências reflexivas sobre o pesquisar em educação. Revista da FUNDARTE. Montenegro, p.01-16, ano 21, № 46, setembro de 2021.

Disponível em: http://seer.fundarte.rs.gov.br/index.php/RevistadaFundarte/issue/archive $>30$ de setembro de 2021. 


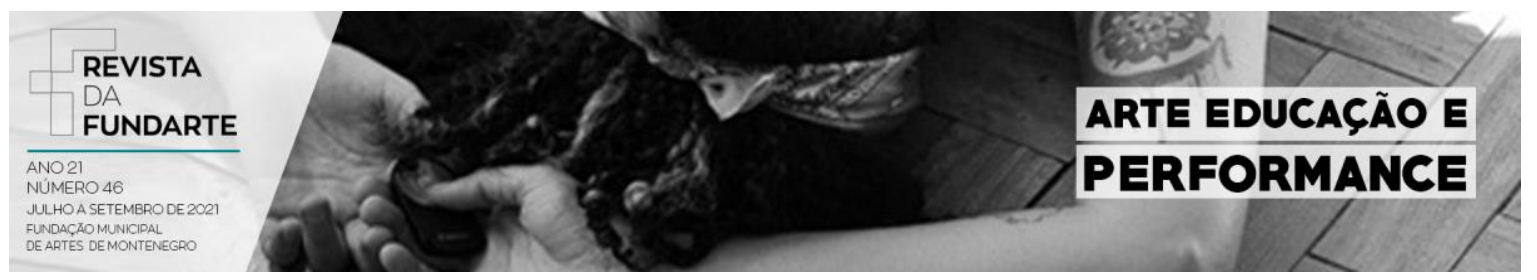

entre aspas, porque regra para mim pode não ser regra para ti e para o outro) é descobrir com o mundo, no mundo, consigo e com o outro o como fazer. $\mathrm{E}$ ainda que a descoberta possa ser compartilhada na sua coletividade, na sua singularidade, ainda que possa se entrelaçar as similaridades que o outro, também, possa percebê-la, ainda assim será a sua descoberta, pessoal e intransferível, que sá, compartilhável, mas não ensinável.

Se eu me conheço? Como posso ter a resposta se estou em plena constituição/construção? Talvez eu seja quando terminar de Ser (a morte), para assim me tornar o que possivelmente posso Ser, não em minha interpretação, mas a partir da interpretação do outro.

Conheces as regras e nelas encontra outras possibilidades para continuar? Posso até conhece-las ou achar (na dúvida) que as conheço, para transgredi-las, se assim for necessário. Descobrirei isso, na experiência, obstante de conhece-la no compartilhamento de outrem que possa dar essa liberdade à regra. Quem a fez? Por que a fez?

É preciso conhecer, através da leitura. É preciso conversar. É preciso escrever. É preciso ver além do que se vê. É preciso ser responsável. É preciso ter compromisso. É preciso ter liberdade. É preciso saber que tudo isso e mais tudo aquilo que possas imaginar a partir disso é nada. Digo isso e muito mais para Mim.

O que eu vou compartilhar? Não sei.

O que eu posso dizer pra $\mathrm{Ti}$, jovem pesquisador | pesquisadora | pesquisadxr?

Não sei.

Pergunto-te: O que dirás pra ti mesmo | mesma | mesmx?

A resposta pode estar em ti mesmo e, também, não existir. Posso compartilhar o que vivi comigo mesmo, contigo, com todos que queiram saber. Ainda assim será o que eu vivi. E o que você viveu? E o que você viverá? E como você viveu? E como você viverá?

ALMEIDA, Bruno Felix da Costa. Em estado-poético: insurgências reflexivas sobre o pesquisar em educação. Revista da FUNDARTE. Montenegro, p.01-16, ano 21, № 46, setembro de 2021.

Disponível em: http://seer.fundarte.rs.gov.br/index.php/RevistadaFundarte/issue/archive $>30$ de setembro de 2021. 


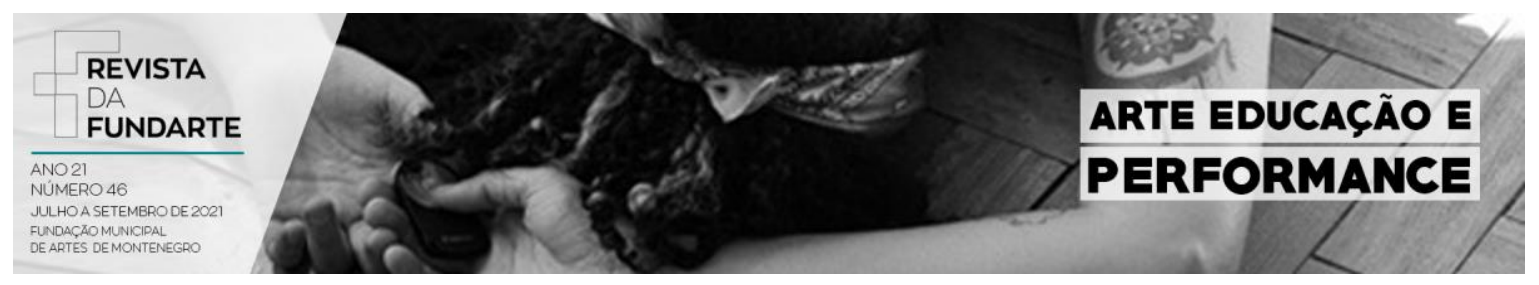

Talvez as respostas sejam pessoais, intransferíveis e ainda assim, talvez, nem as existam.

Talvez escrever uma carta a quem pesquisa seja um mecanismo para dizer a sí próprio - esse quem (pesquisador que se constitui) - o que o faz se constituir. Escrever ao outro, para o outro, mobilizará primeiro aquele que escreve. Afetará o outro se o outro quiser, aceitar, compreender, considerar que tais palavras proferidas por Mim, ou seja lá por quem for, fará e terá sentido para aquele Eu que quero constituir aqui, agora, amanhã e depois e nunca, e se for o caso.

Saber ler, escrever, ter profundidade, ter clareza no que se quer dizer, cabe a necessidade do modo de ser de cada um. Ser "bom" no que se faz. Ser autêntico. Ser o Ser que se quer Ser como quer Ser diante de outro Ser. Ser. Ser. Ser. Quando serei? O que serei? Para quem serei?

Há regras?! Então as descubra e as faça fazer sentido.

Só posso dizer algo para Mim mesmo. Se, aqui, com essas palavras, Tu se mobilizas a fazer delas algo que Tu dirias a Ti mesmo, diante de uma possível compatibilidade (singularidade no coletivo) sobre alguma característica que te move: Ótimo.

As palavras contam sobre quem as escreve.

O "como se faz?" Como posso te dizer o que para mim faz diferença para Ser se só serei, talvez, na completude quando, enfim, findar o ato de Ser presente aqui no mundo. Digo o que sei de um livro a partir de minha interpretação e após lê-lo (por completo, talvez). Então, como posso dizer como fazer se não saberei o "como" antes de concluir o processo? O processo, por completo, terminará quando tudo terminar. Ainda não terminou para Mim, logo entendo que digo o que não sei.

Tudo que escrevo são coisas que não sei. Que digo para Mim. Que compartilho para Ti, para quem sabe, ao dizer para Mim e para o outro e para Nós, possamos encontrar, fazer emergir um entendimento momentâneo sobre aquilo que não sabemos, sobre aquilo que não somos, porque só me resta acreditar que serei um dia. Quando? Quando terminar o meu livro. Que livro? Este que escrevo sendo e

ALMEIDA, Bruno Felix da Costa. Em estado-poético: insurgências reflexivas sobre o pesquisar em educação. Revista da FUNDARTE. Montenegro, p.01-16, ano 21, № 46, setembro de 2021.

Disponível em: http://seer.fundarte.rs.gov.br/index.php/RevistadaFundarte/issue/archive $>30$ de setembro de 2021. 


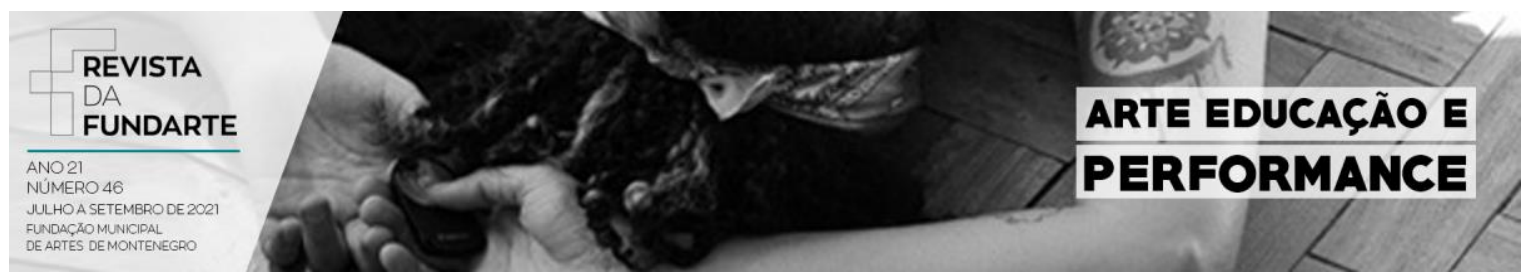

estando aqui, no mundo, com o mundo, e com todos | todas | todxs que nele estão se fazendo estar.

Logo termino não terminando para compartilhar: Carta à um Jovem

\section{Pesquisador: Para quê? Por quê?}

Nessa incessante problematização sobre o Ser aqui, agora, quando e nas infinitudes das mais variáveis possibilidades de Ser e de se pôr a Ser através do pensar na ação de pesquisar, emerge a inquietação de que quando pesquisamos também contamos algo. Contamos, quer seja através da fala e/ou da escrita, a nossa versão dos fatos evidenciados através da nossa ação de pesquisar. Contamos a nossa versão da História.

Mas que História contamos?

É sobre esse contar da História que a reflexão segue. Segue, agora, a partir das inquietações provadas com o estudo do texto de Santos (2019), cuja a historicidade e o reconhecer da historicidade é problematizado por este Eu (professor-pesquisador), na busca incessante sobre a compreensão do pesquisar em educação.

\section{Há História da História}

Ao iniciar essa seção, me proponho a estar presente através dela, a fim tensionar o meu Eu - agora na instância de se fazer presente, a partir de um determinado contexto acadêmico-social - às interlocuções provocadas com as relações do para Mim - sentido mais íntimo, ou seja, no lugar em que eu possa colocar em confronto àquilo que talvez possa ser acolhido por outrem de modo diferenciado em determinados contextos, quer seja positivamente ou não, mas que causam provocações reflexivas em Mim sobre determinados assuntos, problematizando-o para a emergência de conhecimentos. Nesse sentido, coloco em contexto as articulações reflexivas tensionadas em Mim, para em seguida posicionar-me através do meu Eu, diante dessa proposta reflexiva.

ALMEIDA, Bruno Felix da Costa. Em estado-poético: insurgências reflexivas sobre o pesquisar em educação. Revista da FUNDARTE. Montenegro, p.01-16, ano 21, № 46, setembro de 2021.

Disponível em: http://seer.fundarte.rs.gov.br/index.php/RevistadaFundarte/issue/archive $>30$ de setembro de 2021. 


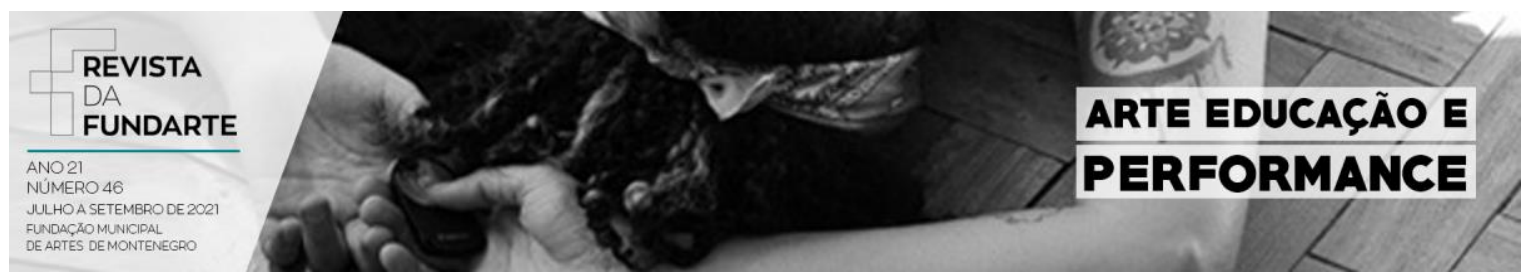

Então, inicio realizando as seguintes problematizações (ou questionamentos) considerando o capítulo intitulado "A desmonumentalização do conhecimento escrito e arquivístico", de Boaventura de Souza Santos (2019):

Primeira problematização: Por quê

desmonumentalizar os conhecimentos monumentais é uma condição prévia para a abertura de espaços argumentativos nos quais outros saberes possam mostrar o seu possível contributo para uma compreensão do mundo mais diversa e mais profunda e para uma transformação social progressista mais eficaz e mais amplamente partilhada [?] (SANTOS, 2019, p. 265-266).

Segunda problematização: Será mesmo necessário "desmonumentalizar os conhecimentos monumentais", que ora foi ou fora constituído em uma perspectiva sobre a qual se contesta, a fim de mostrar contributos à uma compreensão de mundo mais diversificado e profundo?

O "processo" de "desmonumentalizar os conhecimentos monumentais" poderia ser considerado como um processo que, ao invés de "mostrar o seu possível contributo para uma compreensão do mundo mais diversa e mais profunda e para uma transformação social progressista mais eficaz e mais amplamente partilhada", se mostra enquanto um processo que não aceita os conhecimentos monumentais então propostos e apresentados enquanto uma versão verídica dos fatos, para propor uma perspectiva histórica diferenciada, ou seja, ao passo que contesta uma visão sobre determinado conhecimento histórico propondo outra perspectiva/versão de entendimento, estariam eles (os historiadores que propõem a história nessa perspectiva histórica diversificada e profunda) sendo contraditórios, pois desmonumentalizando uma visão para propor-Ihes a sua, poderiam estar em desacordo com a afirmativa sobre considerar o "contributo para uma compreensão do mundo mais diversa", pois ao propor o "desmonumentalizar" uma perspectiva específica não estariam excluindo ao invés de diversificar as possibilidades de entendimento sobre os fatos históricos? (SANTOS, 2019, p. 265-266).

Santos (2019, p. 263) traz a relação da ciência interior, enquanto algo "confuso e desordenado", e a relação da ciência exterior, sendo o "modo como ela se apresenta na espera pública"; e coloca em contraponto a epistemologia do Sul, ALMEIDA, Bruno Felix da Costa. Em estado-poético: insurgências reflexivas sobre o pesquisar em educação. Revista da FUNDARTE. Montenegro, p.01-16, ano 21, № 46, setembro de 2021.

Disponível em: http://seer.fundarte.rs.gov.br/index.php/RevistadaFundarte/issue/archive $>30$ de setembro de 2021. 


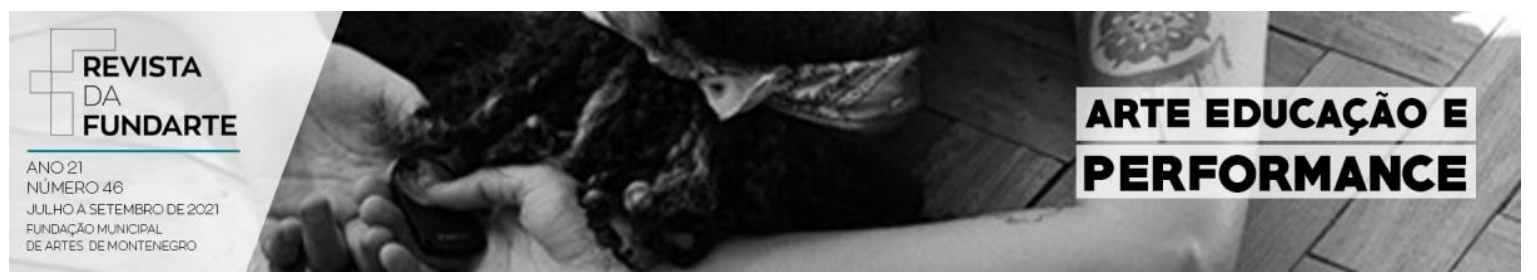

evidenciando a importância de incluí-la junto as ecologias dos saberes, propiciando diferentes aberturas para a apresentação e validação dos conhecimentos, sendo este um dos principais motivos para "uma intervenção desmonumentalizadora" (SANTOS, 2019, p. 264).

O reconhecimento da "oralização", frente ao conhecimento escrito é outro importante aspecto apontado pelo autor. Reconhecer que na oralidade há informações substancialmente essenciais para além das que estão configuradas através da escrita, complementa a perspectiva de uma ecologia de saber que contempla e valoriza, através da oralidade, os conhecimentos que a perspectiva histórica eurocêntrica, por exemplo, não considera.

Transformar a oralidade em informação textual, no entanto, sem a submetê-la a cientificização rigorosa que transforma a fala textualizada em um padrão desnaturalizado de seu contexto de surgimento, tem o seu reconhecimento diante do rigor de sua naturalidade, bem como da força de sua persuasão a partir do contexto que a suscita.

Outra importante relação trazida por Santos (2019), se trata da proposição de Oruka ao reconhecimento do "sábio-filósofo" e do "sábio-popular", evidenciando a importância de que estes possuem diante das realidades sociais e culturais que compartilham seus saberes, bem como do modo que persuadem a importância de seus conhecimentos. Nesse sentido, para ele "tanto Oruka como [Paulo] Freire visam ampliar a conversa do mundo, multiplicando as representações capacitadoras do mundo da autoria de grupos sociais excluídos, dominados ou subalternos" (SANTOS, 2019, p. 274) - o que, de fato, evidencia a importância de se conhecer, na diversidade, a importância dos conhecimentos inerentes a diferentes contextos diante das distintas formas de se propor o reconhecimento dos conhecimentos em um mundo plural.

Ao relacionar o contexto da pesquisa realizada sobre "As vozes do mundo" (SANTOS, 2019, p. 274), apresentando as escolhas dos "agentes, indivíduos e grupos sociais", o autor expõe a possibilidade de compreender, intensamente, a

ALMEIDA, Bruno Felix da Costa. Em estado-poético: insurgências reflexivas sobre o pesquisar em educação. Revista da FUNDARTE. Montenegro, p.01-16, ano 21, № 46, setembro de 2021.

Disponível em: http://seer.fundarte.rs.gov.br/index.php/RevistadaFundarte/issue/archive $>30$ de setembro de 2021. 


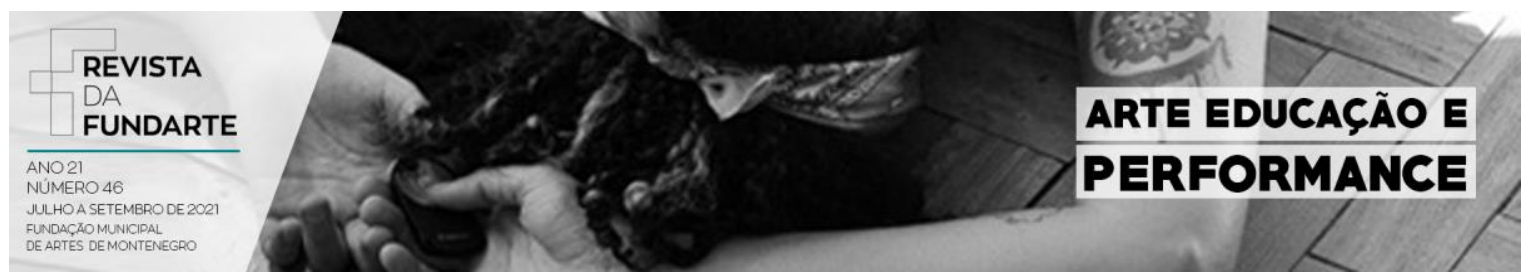

importância de dar voz e vez àqueles que também constituem e contribuem com os seus conhecimentos à transformação do mundo (SANTOS, 2019, p. 278).

Então, após esta contextualização sobre a importância de se reconhecer a fala contextual e histórica, Santos (2019, p. 280) esclarece que "o arquivo dominante é a forma abissal moderna de produzir conhecimento sob pretexto de armazenar", o que acarreta na distinção e na escolha sobre qual o conhecimento merece ser contemplado à armazenagem e qual estará à mercê do descarte.

Portanto, para ele, "o arquivo moderno é cartógrafo 'oficial' da linha abissal", e configura uma dupla negação: a primeira, de critério colonial, que "apagou como ausências, irrelevâncias e invisibilidades de tudo aquilo que pudesse denunciar o caráter abissal da sociedade e sociabilidade metropolitana" (SANTOS, 2019, p. 280); enquanto que, a segunda negação, que trata sobre a dominação colonialista, "tornou possível a extração daquilo que é registrado" (SANTOS, 2019, p. 281).

O descarte informacional apontado é considerado por Santos (2019) como "epistemicídio", ou seja, é descartado a fim de trazer à luz de quem tem acesso à informação conhecimentos que são selecionados a partir de uma perspectiva de pertinência colonialista.

Logo, encaminha-se a relação da epistemologia do sul frente ao arquivo abissal, a qual possibilita, enquanto um artefato epistêmico - "sujeito a uma interrupção epistemológica e metodológica" (SANTOS, 2019, p. 281) - tornar possível o apontamento de quatro especificidades, quais sejam: "Contas acertadas", que mostra o passado e não propicia ao seu retorno, possibilidade de novos questionamentos, mas se mostra imutável; "Monumentalidade", que se refere aos objetos e documentos que são preservados nos arquivamentos realizados; "Docilidade", que considera que o arquivo dessa especificidade pode ser enganador, "pois a qualquer momento a sua seletividade nega-se a si mesma na medida em que apenas reflete aquilo que está disponível" (SANTOS, 2019, p. 283); e "Ambiguidade", configura-se enquanto um tipo de arquivo com o "sentido solto,

ALMEIDA, Bruno Felix da Costa. Em estado-poético: insurgências reflexivas sobre o pesquisar em educação. Revista da FUNDARTE. Montenegro, p.01-16, ano 21, № 46, setembro de 2021.

Disponível em: http://seer.fundarte.rs.gov.br/index.php/RevistadaFundarte/issue/archive $>30$ de setembro de 2021. 


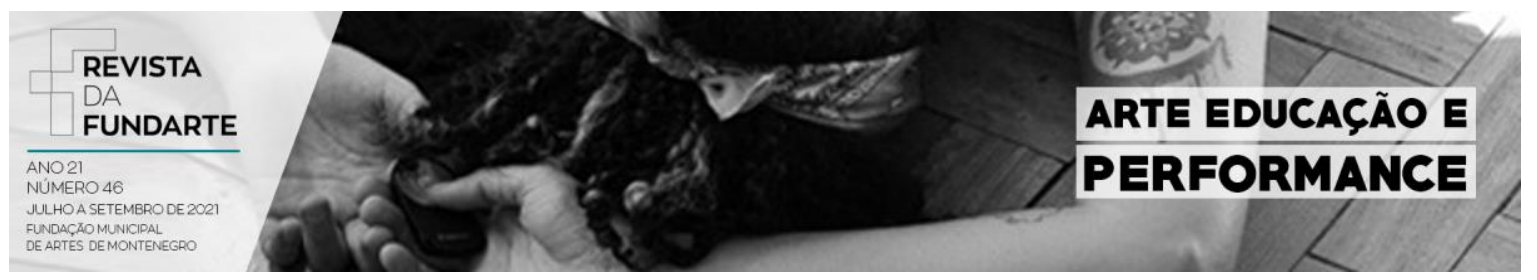

indeterminado, que carrega consigo as sementes da contestação e da contradição" (SANTOS, 2019, p. 283).

Nesse sentido, em considerando essas especificidades, o autor evidencia a vulnerabilidade dos arquivos abissal, relacionando que "as epistemologias do sul propõem duas interrupções do arquivo abissal: o arquivo palimpsesto, orientado para a sociologia das ausências, e o arquivo insurgente, orientado para a sociologia das emergências" (SANTOS, 2019, p. 283). Sendo estes possuidores de "critérios plurais de autoridade para que um arquivo não autorizado não seja um arquivo sem autoridade" (SANTOS, 2019, p. 283).

O arquivo-palimpsesto [...] consiste em raspar a superfície daquilo que o arquivo mostra a fim de identificar as marcas, sinais e silêncios do que foi destruído ou produzido como ausente, invisível e irrelevante no processo de construção do mundo passível de ser arquivo (SANTOS, 2019, p. 283-284).

Por outro lado,

o arquivo insurgente rompe com a forma de arquivo, dispersando-a por uma multiplicidade de sítios e de tipos de prática que visam arquivar, mesmo se de forma efêmera, um presente não oficial e não autorizado, um presente denso cuja força advém da reivindicação de um passado suprimido. (SANTOS, 2019, p. 285-286).

Essas possibilidades propostas para o tratamento das fontes históricas conduzem à outras formas de se relacionar com a museologia, podendo ter diferentes denominações, tais como: "museologia popular, museologia ativa, ecomuseologia, museologia comunitária”, dentre outras (SANTOS, 2019, p. 287).

Contudo, a importância de se reconhecer outras perspectivas da mesma história se faz importante, frente às proposições apontadas por Santos (2019), no sentido de evidenciar as vozes daqueles que também constituem a história.

Reconhecer que Há Histórias, ou seja, formas diferentes de se contar a mesma informação, torna possível à contribuição daqueles que tem na oralidade sua importância, à leitura do objeto a partir do que ele próprio carrega em sí. É nesse sentido que, em Mim, emergiram as duas problematizações supracitadas, a fim de provocar outras inquietações em outras Pessoas, sobre as insurgências arquivísticahistóricas.

ALMEIDA, Bruno Felix da Costa. Em estado-poético: insurgências reflexivas sobre o pesquisar em educação. Revista da FUNDARTE. Montenegro, p.01-16, ano 21, no 46, setembro de 2021.

Disponível em: http://seer.fundarte.rs.gov.br/index.php/RevistadaFundarte/issue/archive $>30$ de setembro de 2021. 


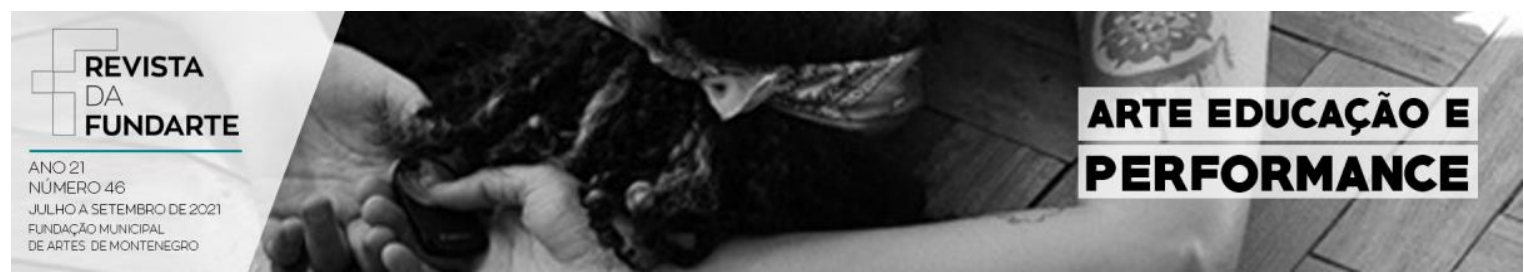

\section{Outra Introdução, Para Não Finalizar}

Os desafios de Ser músico-docente-pesquisador nesse Tempo-Planetário2020, colou-me a refletir sobre o "Aprender a conhecer" através da docência, da pesquisa e da universidade; colou-me a refletir sobre o "Aprender a fazer" como músico, como professor e como pesquisador em Educação; colocou-me a intensificar às relações de "Aprender a viver juntos, aprender a viver com os outros", percebendo no coletivo a singularidade de pensamentos sobre um mesmo assunto; além de me propiciar a "Aprender a ser", posicionando-me diante de minha singularidade de Ser na pluralidade de viver nesse planeta repleto de cegueiras, erros e ilusões, como bem nos ressalta Edgar Morin.

É necessário estarmos no mundo e com o mundo. A racionalidade e o simbólico, enquanto linguagem, por ora separam-se. Religá-los para pô-los em sintonia com o real e o complexo faz desse ato o nosso desafio humano, do humano, nas vias de existência no e com o mundo.

A compreensão sobre algo pode estar no ato de reconhecer os próprios limites e no respeitar o limite do outro. Pode estar no reconhecer que saber tudo não é sabedoria. Como bem lembra Edgar Morin, sabedoria é saber que não se sabe.

Nesse sentido, estar em estado-poético viabiliza a conexão desse Eu as possibilidades de descobertas, de conhecimentos, de reconhecimentos. Viabiliza as possibilidades de saber que o que hoje se sabe, se transforma e pode ser diferente amanhã. Viabiliza saber que nada está pronto e tudo está em andamento - em acontecimento. Está sendo agora o que poderá não ser mais no próximo segundo, talvez.

São sobre conselhos, sobre versões de fatos, sobre palavras que contam as coisas que são e ao mesmo tempo podem não ser; são sobre reflexões em constante transformação que as palavras escritas, aqui, dizem sobre quem as escreve e que podem ser acolhidas por quem as lê.

ALMEIDA, Bruno Felix da Costa. Em estado-poético: insurgências reflexivas sobre o pesquisar em educação. Revista da FUNDARTE. Montenegro, p.01-16, ano 21, № 46, setembro de 2021.

Disponível em: http://seer.fundarte.rs.gov.br/index.php/RevistadaFundarte/issue/archive $>30$ de setembro de 2021. 


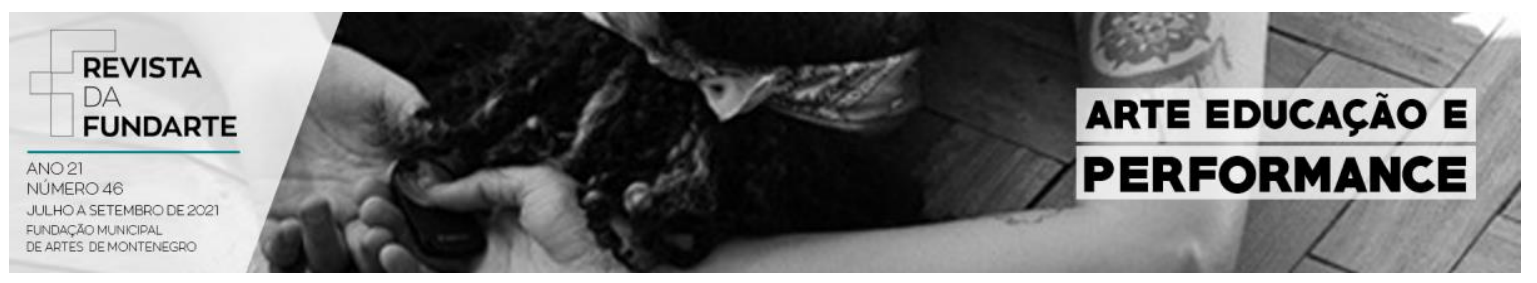

São sobre o Tempo, o Espaço e o Ser que as palavras remetem. A relação desse ensaio às inquietudes de quem o escreve também são. São sobre pesquisa, sobre educação, sobre história e histórias que podem ser através da ação que as dá vida, forma e sentido - o pesquisar.

Pesquisar em Educação é nesse instante de escrita, o ato de questionar: se posso me colocar em estado-poético, que insurgências sobre a ação de pesquisa em educação posso refletir?

Então, sem concluir e sem dar conselhos, pergunto: $O$ que é pesquisar a música em educação?

\section{Referências:}

DELORS, Jacques et al. Os quatro pilares da educação. In: DELORS, Jacques et al. Educação um tesouro a descobrir: relatório para a UNESCO da Comissão Internacional sobre Educação para o século XXI. Brasília, DF: UNESCO, 1996.

HEIDEGGER, Martin. Ser e Tempo. 10 ${ }^{\mathrm{a}}$ Ed. Petrópolis, RJ: Vozes: Bragança Paulista, SP: Editora Universitária São Francisco, 2015.

HERRIGEL, Eugen. A arte Cavalheiresca do arqueiro Zen. São Paulo: Pensamento, 1995.

KRAEMER, Rudolf-Dieter. Dimensões e funções do conhecimento pedagógicomusical. Em Pauta, Porto Alegre, V.11, n. 16/17, abr./nov., p.50-73, 2000.

MORIN, Edgar. Ensinar a viver: manifestos para mudar a educação. Porto Alegre: Sulina, 2015.

NÓVOA, António. Carta a um jovem investigador em educação. Investigar em Educação - III Série, Número 3, 2015.

SANTOS, Boaventura de Sousa. A desmonumentalização do conhecimento escrito e arquivístico. In: SANTOS, Boaventura de Sousa. O fim do império cognitivo: a afirmação das epistemologias do sul. Belo Horizonte: Autêntica Editora, 2019.

ALMEIDA, Bruno Felix da Costa. Em estado-poético: insurgências reflexivas sobre o pesquisar em educação. Revista da FUNDARTE. Montenegro, p.01-16, ano 21, № 46, setembro de 2021.

Disponível em: http://seer.fundarte.rs.gov.br/index.php/RevistadaFundarte/issue/archive $>30$ de setembro de 2021. 